\title{
ANIMALES E INCAS EN EL OESTE TINOGASTEÑO (CATAMARCA, ARGENTINA)
}

\author{
Juan Pablo Miyano, Irene Lantos, Norma Ratto y Martín Orgaz
}

\begin{abstract}
Este trabajo explora las múltiples dimensiones de las prácticas humanas relacionadas al uso de los animales durante la ocupación incaica del oeste tinogasteño (Catamarca, Argentina). Se sostiene que el Estado inca patrocinó fiestas en el sitio de San Francisco (puna transicional de Chaschuil), donde se consumió y compartió principalmente carne de animales silvestres, destacándose el consumo de carne y médula ósea de vicuñas adultas. Estos camélidos silvestres fueron capturados mediante el chaku, un tipo de cacería comunal sumamente regulada. Sin embargo, los animales no solo fueron usados como fuente de alimento: las llamas también fueron empleadas como animales de carga. Los incas unieron San Francisco con sitios tan lejanos como Batungasta (valle de Fiambalá) mediante caravanas. Estas caravanas de llamas transportaron aríbalos y aribaloides desde Batungasta, un centro de producción alfarero, hacia San Francisco. Dado que estas vasijas fueron diseñadas para contener y servir bebidas alcohólicas, sus paredes internas debieron estar impermeabilizadas: la médula ósea de camélido habría sido utilizada para ese propósito. Finalmente, en San Francisco se emplearon huesos de aves y roedores para manufacturar artefactos. Probablemente, la piel de un puma, animal de gran importancia simbólica entre los incas, fue procesada en el sitio.
\end{abstract}

This paper explores the diverse human practices related to the use of animals during the Inca occupation of west Tinogasta (Catamarca, Argentina). We argue that the Inca state sponsored festivities in the San Francisco site (transitional puna of Chaschuil), where wild animal meat, mainly meat and bone marrow of adult vicuñas, was shared and consumed. These wild camelids were captured during the chaku, a collective hunting regulated by social and cultural mechanisms. Llamas were used as beasts of burden in caravans transporting ceramic vessels (aríbalos and aribaloides) from the pottery production center of Batungasta to San Francisco. We postulate that the aríbalos and aribaloides, which were designed for alcoholic beverages, were lined with camelid bone marrow to make their inner walls impermeable. Lastly, we argue that bones of birds and rodents were used to and the skin of a puma (important symbolic animal for the Incas) was processed in the San Francisco site.

\section{La Dominación Incaica en el Collasuyu}

$\mathrm{E}$ 1 imperio inca fue una de las configuraciones sociales más complejas desarrolladas en la región andina. Desde Cusco, inició un proceso expansivo mediante el cual incorporó bajo su dominio un gran número de poblaciones y un extenso territorio. El Collasuyu fue la más grande de las cuatro unidades geopolíticas en que el Estado inca dividió su imperio, comprendiendo una amplia área de los Andes meridionales (altiplano boliviano, norte y centro de Chile y noroeste y centro-oeste de Argentina) (Raffino 1981; Williams et al. 2009). Durante su expansión, el Estado inca implementó diversas estrategias de dominación que se adaptaron a contextos locales para controlar y administrar los territorios anexados y sus poblaciones (p.ej., D'Altroy et al. 2000; Malpass 1993; Malpass y Alconini 2010; Williams

Juan Pablo Miyano — Universidad de Buenos Aires, CONICET, Instituto de las Culturas (UBA-CONICET), Facultad de Filosofía y Letras, Museo Etnográfico Juan B. Ambrosetti, Ciudad Autónoma de Buenos Aires, Argentina (jpmiyano@gmail.com)

Irene Lantos — Universidad de Buenos Aires, CONICET, Unidad de Microanálisis y Métodos Físicos Aplicados a Química Orgánica, Facultad de Ciencias Exactas y Naturales, Ciudad Autónoma de Buenos Aires, Argentina

Norma Ratto - Universidad de Buenos Aires, Instituto de las Culturas (UBA-CONICET), Facultad de Filosofía y Letras, Museo Etnográfico Juan B. Ambrosetti, Ciudad Autónoma de Buenos Aires, Argentina

Martín Orgaz Universidad Nacional de Catamarca, Escuela de Arqueología, San Fernando del Valle de Catamarca, Catamarca, Argentina 
2000; Williams et al. 2009). Los incas ocuparon diversos ambientes del Collasuyu con diferente intensidad, construyendo enclaves administrativos, centros productivos y sitios ceremoniales. Las instalaciones de mayor envergadura se encontraban conectadas por una red vial de amplia extensión conformada por dos caminos principales longitudinales conectados mediante caminos transversales (D'Altroy 2002; Williams 2000).

El dominio inca en el Collasuyu supuso la intensificación de la producción artesanal, minera, agrícola y pastoril (D'Altroy 2002). La intensificación en la explotación de animales se concentró en los camélidos y condujo a un proceso de especialización, tanto en especies domesticadas como silvestres. Con respecto a las primeras, las dos estrategias más importantes consistieron en segregar llamas en rebaños específicos para la producción de recursos primarios (carne) o secundarios (fibra o carga) (Mengoni Goñalons 2007). Con respecto a las especies silvestres, la caza de vicuñas fue selectiva y se restringió a eventos especiales (Ratto y Orgaz 2004). El presente trabajo tiene como objetivo abordar las prácticas humanas vinculadas al manejo y aprovechamiento de animales durante la ocupación incaica del oeste tinogasteño mediante el análisis de conjuntos arqueofaunísticos y fragmentos cerámicos provenientes del sitio de San Francisco, ubicado en la puna transicional de Chaschuil, Catamarca, Argentina.

\section{Aprovechamiento de Animales en el Collasuyu}

Las sociedades andinas del pasado prehispánico aprovecharon los animales de diversas maneras: los usaron como fuente de alimento, los emplearon con fines tecnológicos y los incorporaron a sus sistemas simbólicos. Los camélidos -de gran importancia para estas sociedades- fueron objeto de los tres usos mencionados (p. ej., Mengoni Goñalons 2013; Olivera 1997; Yacobaccio 2009: Yacobaccio et al. 1998). A continuación se sintetizan las principales tendencias en el aprovechamiento de animales en sitios del Collasuyu emplazados en dos grandes áreas: a) ambientes de costa, valles y quebradas ubicados a menos de $3500 \mathrm{msnm}$, y b) ambientes de puna o altiplano, localizados por encima de los $3500 \mathrm{msnm}$.

\section{Antecedentes zooarqueológicos en sitios de costa, valles y quebradas}

Los estudios zooarqueológicos realizados en instalaciones del Collasuyu se concentran principalmente en sitios emplazados por debajo de los 3500 msnm, en Chile (Cartajena et al. 2014; Garceau et al. 2010; López et al. 2015; Rivera et al. 2014; Troncoso et al. 2004) y en Argentina (Bárcena et al. 2008; Couso et al. 2011; D’Altroy et al. 2000; García Llorca 1995; Lema et al. 2009; Madero 1994; Mengoni Goñalons 2013; Rodríguez Loredo 1998). La predominancia de camélidos es absoluta, destacándose tanto los domesticados (Lama glama) como los silvestres (Vicugna vicugna y probablemente Lama guanicoe). Se identificaron dos estrategias de pastoreo: una relacionada con la producción primaria (carne) y otra con la producción secundaria (fibra o carga). Los conjuntos arqueofaunísticos de los distintos sitios sugieren que la estrategia predominante varía dependiendo del emplazamiento. Así, por un lado, en el sitio de Tolombón (valles Calchaquíes, Salta, Argentina) se registra una clara supervivencia de las llamas por encima de los 2-4 años, lo que indicaría la conservación de animales para la producción secundaria (Mengoni Goñalons 2013). Esta estrategia también se observa en La Huerta, Papachacra (Madero 1994), Potrero Chaquiago (Rodríguez Loredo 1998), MAU094 y MAU067 (Rivera et al. 2014). Por otro lado, en Potrero Payogasta, también ubicado en los valles Calchaquíes, se observa que la mayoría de las llamas fueron sacrificadas entre los 24 años de vida, de modo que la estrategia se orientó a la producción primaria (D'Altroy et al. 2000). Esta estrategia se implementó también en Esquina Huajra y Pucará de Volcán (Mengoni Goñalons 2013). Las llamas fueron íntegramente aprovechadas: su carne sirvió como alimento, su fibra se utilizó para la producción de textiles y su capacidad de carga se empleó para el transporte de recursos y bienes.

En los sitios del Collasuyu fueron cazados diversos animales silvestres. En Papachacra (valles orientales de Jujuy, Argentina) se registra una amplia presencia de cérvidos. Madero (1994) 
explica esta persistencia de la caza como un modo de evitar la reducción de los rebaños de llamas. En El Shincal de Quimivil (Catamarca, Argentina) se registra el aprovechamiento de animales silvestres locales: aves, roedores, dasipódidos (Couso et al. 2011; Lema et al. 2009) y peces del orden Siluriformes (Giovannetti 2015). En el curso superior del río Illapel (IV Región, Chile), el sitio Césped 3 presenta restos de fauna marina (jurel y moluscos) (Troncoso et al. 2004), los cuales también son registrados en el sitio costero LV099-B (Troncoso et al. 2009). Finalmente, Rodríguez Loredo (1998) enfatiza la abundancia y diversidad de aves y roedores en Potrero Chaquiago (Catamarca, Argentina). Sin embargo, los taxones silvestres más explotados fueron los camélidos. La presencia de vicuña ha sido registrada en Chile (Cartajena et al. 2014; López et al. 2015) y en Argentina, en sitios como Tambo La Alcaparrosa (Quebrada Alcaparrosa, San Juan) (Bárcena et al. 2008), Tambo Tambillos (valle de Uspallata, Mendoza) (García Llorca 1995), Potrero Chaquiago (bolsón de Andalgalá, Catamarca) (Rodríguez Loredo 1998), El Shincal de Quimivil (valle de Hualfín, Catamarca) (Couso et al. 2011) y distintos sitios de la Quebrada de Humahuaca, valles orientales de Jujuy y valles Calchaquíes (D'Altroy et al. 2000; Madero 1994; Mengoni Goñalons 2013). Es interesante destacar la presencia de vicuñas en sitios emplazados a menos de 3500 msnm, dado que el hábitat de estos camélidos se limita a la puna. Esto sugiere la interacción de aquellos que ocuparon sitios de valles y quebradas con ambientes más altos. Las vicuñas poseían un lugar especial dentro del sistema simbólico inca, siendo consideradas como "ganado de las divinidades" (Dedenbach-Salazar Sáenz 1990:192) y su captura se encontraba sumamente regulada por mecanismos sociales, políticos, culturales y religiosos (Ratto y Orgaz 2004, 2008; Yacobaccio 2009).

\section{Antecedentes zooarqueológicos en sitios de puna o altiplano}

Los análisis zooarqueológicos de sitios inca del Collasuyu ubicados a más de $3500 \mathrm{msnm}$ son escasos. Se destacan los estudios realizados en Campo Cortaderas (Antofagasta de la Sierra, Catamarca, Argentina) (Olivera et al. 2005),
Miño 2 (Alto Loa, Antofagasta, Chile) (Labarca y López 2010) y Tambo Cañapa, (Altiplano de Lípez, Potosí, Bolivia) (Nielsen et al. 2006). Los tres sitios muestran una gran representación de animales silvestres como camélidos, aves y roedores. Si bien en Campo Cortaderas se registraron llamas, en Miño 2 y en Tambo Cañapa estos camélidos están ausentes. Nielsen y coautores (2010) explican que su ausencia se debe a que los grupos que transitaron la región lacustre altoandina se aprovisionaron de carne mediante la caza de animales silvestres. Labarca y López (2010) sostienen que la presencia exclusiva de animales silvestres en Miño 2 responde a la celebración de festines, lo cual se encuentra apoyado por la asociación con vasijas destinadas a contener líquidos y servir alimentos. Un registro zooarqueológico y cerámico similar es reportado por Berenguer y coautores (2011) en Tambo de Collahuasi (Altiplano de Tarapacá, Chile), donde también se celebraron festines estatales. Ambos casos configurarían agasajos para retribuir a los trabajadores que servían en las minas de la zona con el objetivo de reafirmar el control sobre éstos y garantizar el funcionamiento de los enclaves (Berenguer 2007).

Ratto y Orgaz (2004) reportan la presencia de dos macroestructuras de caza ubicadas en Cazadero Grande (puna transicional de Chaschuil, Catamarca). La evidencia contextual sugiere que se utilizaron en momentos incaicos para la conducción y encierro colectivo de vicuñas, práctica conocida como chaku. Distintas fuentes etnohistóricas concuerdan en que la matanza de vicuñas estaba sumamente regulada dentro del imperio inca (Ratto y Orgaz 2008). Mediante el chaku, se capturaba una gran cantidad de individuos y se producía, por un lado, la esquila y posterior liberación de gran parte de las vicuñas (principalmente, hembras y machos jóvenes) y, por otro lado, la matanza selectiva de animales viejos o enfermos los cuales eran aprovechados íntegramente (Dedenbach-Salazar 1990; Ratto y Orgaz 2004; Yacobaccio 2009).

En suma, las características de los conjuntos arqueofaunísticos son variables y están sujetas al contexto arqueológico, al rol del sitio de donde provienen y a su ubicación ambiental (Mengoni Goñalons 2013). La zooarqueología del Collasuyu posee un sesgo hacia aquellos emplaza- 


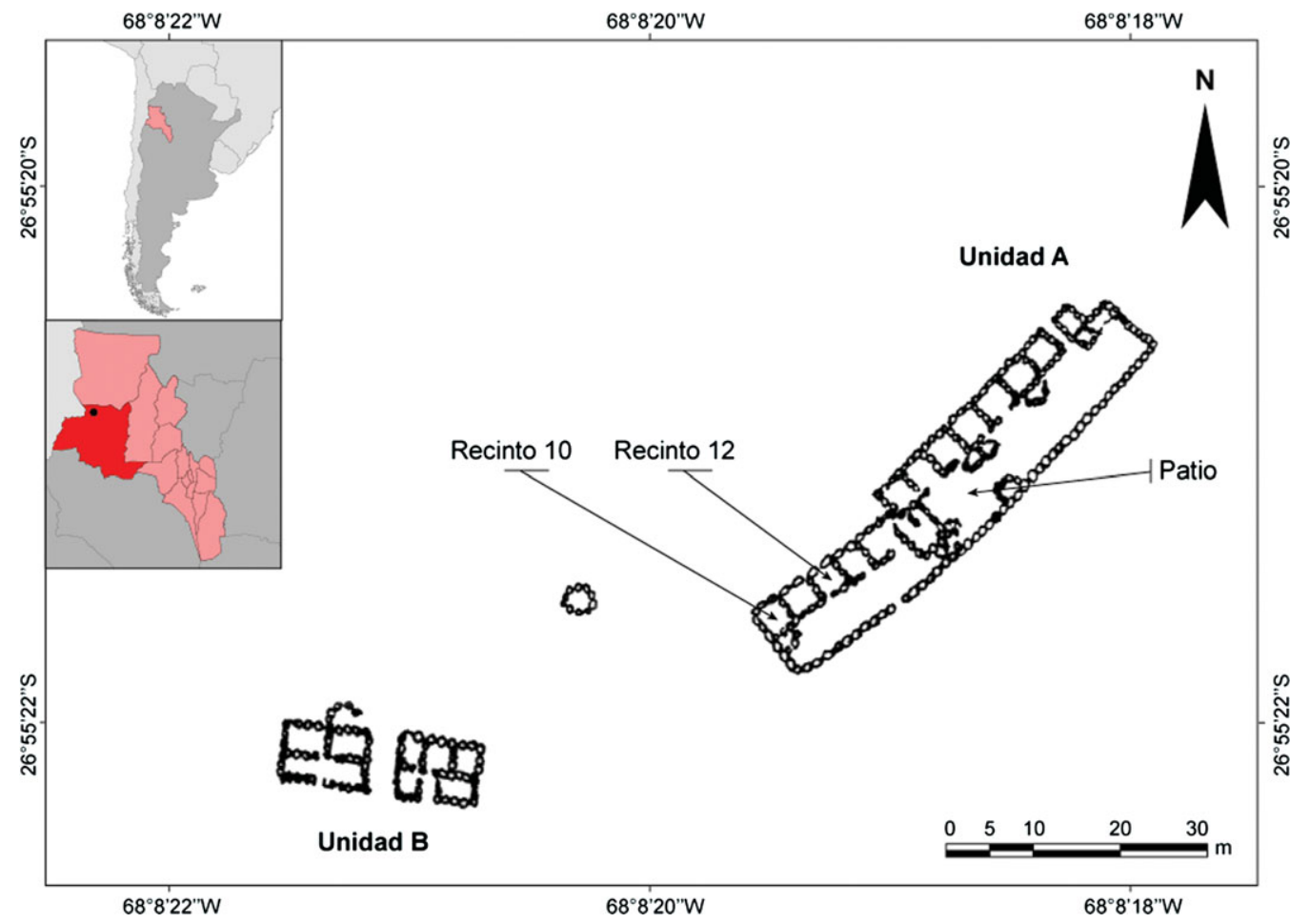

Figura 1. Ubicación del sitio de San Francisco y mapa de las estructuras y áreas intervenidas. (Color online)

mientos ubicados en valles y quebradas, siendo escasos los estudios realizados en sitios de cotas altitudinales mayores. Para obtener una perspectiva amplia de las estrategias implementadas por el Estado inca en el Collasuyu es necesario considerar sitios ubicados en distintos ambientes. El presente trabajo propone abordar el manejo y uso de los animales durante la ocupación incaica del oeste tinogasteño (Catamarca, Argentina). Para ello, se analiza el material arqueofaunístico y cerámico proveniente de las intervenciones realizadas en el sitio de San Francisco, emplazado en la puna transicional de Chaschuil. Los resultados se discuten en la escala del sitio y con relación a Batungasta, otro sitio inca del oeste tinogasteño ubicado en el valle de Fiambalá. Ambos ambientes contrastantes se comunican a través de conectores naturales (Ratto et al. 2012).

\section{San Francisco: Un Sitio Inca en la Puna Transicional de Chaschuil}

San Francisco se emplaza en la puna transicional de Chaschuil (Catamarca, Argentina), a 4000 msnm, en el borde de la vega homónima. Su arquitectura responde a un patrón incaico y está compuesta por dos RPC (Rectángulo Perimetral Compuesto [sensu Madrazo y Ottonello 1966]) separados por aproximadamente $35 \mathrm{~m}$. La Unidad A cuenta con 15 recintos que convergen en un espacio de mayores dimensiones cerrado por el muro perimetral, cubriendo una superficie de $273,8 \mathrm{~m}^{2}$. La Unidad B, cuya superficie es de $80,6 \mathrm{~m}^{2}$, posee ocho recintos (Figura 1). Hacia el oeste, se detectaron estructuras circulares consideradas como collqas (estructuras destinadas al almacenamiento de recursos). Los fechados radiométricos indican que la construcción incaica fue levantada sobre un espacio ocupado por sociedades previas. Debajo de la primera hilera de cimientos del Recinto 10 se registró un fogón que arrojó fechados para fines del primer milenio de la era: $1030 \pm 60$ a.P. (LP-716; carbón) y $940 \pm$ 80 a.P. (LP-676; carbón). Por su parte, el Nivel 4 del Recinto 12 posee un fechado de $800 \pm$ 70 años a.P. (LP-3162; apatita ósea). Esto es coincidente con la alta densidad de fragmentos 
cerámicos en superficie, cuyas características tecno-morfo-decorativas permiten adscribirlos a las sociedades productivas del primer milenio, y con los fechados obtenidos por termoluminiscencia (Ratto 2013). Pese a no contar con limitaciones topográficas, el Estado inca eligió una disposición arquitectónica previa para asentarse, conformándose un espacio multicomponente.

Los fechados correspondientes a la ocupación incaica provienen del Nivel 2 del Recinto 12 (LP$3169 ; 570 \pm 50$ años a.P.; apatita ósea) y del Nivel 2 de un espacio interno abierto considerado como patio (LP-3173; $570 \pm 60$ años a.P.; apatita ósea). El registro cerámico asociado se compone exclusivamente de piezas destinadas al almacenaje y servido de alimentos (aríbalos, aribaloides y platos pato), cuya manufactura se llevó a cabo en Batungasta, sitio emplazado en el valle de Fiambalá, Catamarca, a 1480 msnm, en función de los estudios de procedencia realizados (Orgaz et al. 2007; Ratto et al. 2002). Dadas las características del conjunto cerámico, se propuso que en San Francisco se llevaron a cabo actividades ceremoniales restringidas y patrocinadas por el Estado, donde se consumieron y compartieron alimentos y bebidas alcohólicas (Orgaz et al. 2007). Además, su ubicación geográfica se encuentra relacionada con la ruta de ascenso a la cumbre del volcán Incahuasi (6638 msnm), donde se reportó un santuario de altura inca con importantes ofrendas (Orgaz y Ratto 2015).

\section{Materiales y Métodos}

Se estudiaron dos materialidades arqueológicas diferentes. Por un lado, se analizó el material arqueofaunístico proveniente de los niveles fechados para momentos incaicos. El conjunto óseo se compone de 2607 especímenes: 1176 provienen del Recinto 12 (R12) y 1431 del patio. Por otro lado, se estudió parte del material cerámico para investigar si la grasa animal fue empleada para el tratamiento de sellado de las vasijas destinadas a contener bebidas (Bray 2008). La cerámica recuperada en San Francisco consta de 69 fragmentos agrupados en un número mínimo de piezas cerámicas de 14: cuatro aríbalos, nueve aribaloides y un plato pato (Orgaz et al. 2007). En este trabajo se analizaron cuatro piezas -dos aríbalos y dos aribaloides- procedentes del R12 y del patio y asociadas al material arqueofaunístico mencionado.

\section{Métodos para el análisis del material arqueofaunístico}

La identificación anatómica y taxonómica del material arqueofaunístico se realizó a partir de la comparación con colecciones óseas de referencia y la consulta de atlas osteológicos. Los especímenes óseos identificados se asignaron a diversas categorías taxonómicas, conformando el número de especímenes identificados (NISP) (Lyman 2008). La utilización de categorías taxonómicas menos inclusivas estuvo sujeta a la presencia de zonas diagnósticas en los restos óseos (Mengoni Goñalons 1999). En cambio, su ausencia obligó al uso de categorías más inclusivas, considerando rasgos como curvatura, espesor, cualidades estructurales y tamaño de los especímenes (De Nigris 2004). Aquellos restos que no fueron incluidos dentro de ninguna categoría taxonómica se considera ron como no-identificables (NID) (Mengoni Goñalons 1999).

La medición de los elementos del esqueleto apendicular permite discriminar dos grupos de tamaños de camélidos: grandes (guanaco y llama) y pequeños (vicuña y alpaca). Debido a que las condiciones ambientales de la puna argentina no son aptas para la cría de alpacas (Mengoni Goñalons 2008), es altamente probable que en el pasado prehispánico solo hayan habitado tres de las cuatro especies de camélidos: vicuñas, guanacos y llamas. Se realizaron análisis osteométricos para diferenciar grupos de tamaños de camélidos. Así, se eligieron especímenes óseos bien conservados, fusionados, sin termoalteración (Elkin et al. 1991) y que presentaran los puntos de medición propuestos por von den Driesch (1976). Se seleccionó una dimensión por cada hueso: ancho del extremo distal (Bd) del húmero, del radioulna, del fémur y del metapodio; ancho máximo de la cara articular proximal (Bp) de la tibia; y ancho máximo de la cara articular proximal (Bfp) de la falange 1 y de la falange 2 (von den Driesch 1976). Cada medida de cada espécimen arqueológico se comparó con su equivalente, tomada de un camélido de referencia actual (guanaco de las Cumbres Calchaquíes 
analizado por Elkin y Mengoni Goñalons; Mengoni Goñalons, comunicación personal 2016). Dicha comparación se realizó mediante la fórmula de diferencia de logaritmos: $d l=$ $\log (x)-\log (z)=\log (x / z)$ (Meadow 1987). Así, se obtuvo la diferencia entre el valor de la medida del espécimen arqueológico $(x)$ y su equivalente del guanaco actual $(z)$. De este modo, siguiendo a López (2003), se consideró que un valor de diferencia logarítmica menor a $-0,02$ sugiere la presencia de un camélido de tamaño pequeño, atribuible a vicuña dada la baja probabilidad de presencia de alpaca en el noroeste argentino. Por otro lado, un valor de diferencia logarítmica mayor a 0,02 supone que el espécimen arqueológico posee un tamaño grande, atribuible a llama. Los valores intermedios (entre $-0,02$ y 0,02) sugieren que el espécimen podría pertenecer tanto a llama como a guanaco. En estos casos, se utilizó la categoría "llama-guanaco", la cual no señala la presencia de una especie sino a aquellos casos en los que existe una superposición de tamaño corporal.

Con respecto a la abundancia taxonómica, se calculó el MNE de Camelidae a partir del método de zonas diagnósticas y la suma de fracciones, considerando variables tales como lateralidad, estado de fusión y tamaño relativo de los especímenes. Complementariamente, se obtuvo el MAU y \%MAU (Binford 1978, 1984). Además, se calculó la relación entre el MNE observado en el conjunto arqueofaunístico (MNEO) y el MNE esperado de un esqueleto completo de camélido (MNEE) para siete regiones anatómicas (De Nigris 2004). Estas regiones se dividieron considerando la cantidad relativa de carne y médula que ofrecen: a) la columna (vértebras y sacro; $\mathrm{MNEE}=27$ ), el costillar (costillas y esternebras; $\mathrm{MNEE}=30$ ) y las cinturas (escápula e innominado; $\mathrm{MNEE}=4$ ) ofrecen solo carne; b) las extremidades superiores (húmero y fémur: $\mathrm{MNEE}=4$ ) brindan abundante carne y médula; c) las extremidades medias (radioulna y tibia; $\mathrm{MNEE}=4$ ) otorgan poca carne y médula; d) las extremidades inferiores (metapodios y falanges 1 y 2 ; MNEE $=20$ ) ofrecen solo médula en proporciones moderadasbajas; y e) la cabeza (hemicráneo y hemimandíbula; $\mathrm{MNEE}=4$ ) contiene órganos ricos en grasa (Borrero 1990; De Nigris y Mengoni
Goñalons 2005). La relación entre MNEE y MNEO se estandarizó en una escala de 0 a 100.

Con el objetivo de explorar las estrategias de pastoreo y caza, se construyeron perfiles etarios considerando el estado de fusión de especímenes de camélidos de dos tamaños diferentes. Los restos óseos considerados corresponden a la escápula, el innominado, los huesos largos y las primeras falanges, cuyas edades de fusión se agrupan en tres etapas no superpuestas: fusión temprana (12 a 18 meses), fusión intermedia (18 a 36 meses) y fusión tardía (36 a 48 meses) (Mengoni Goñalons 2013:Tabla 3). Para abordar las prácticas pastoriles, se construyeron perfiles etarios a partir de especímenes, ya sea fusionados o no fusionados, que por su tamaño mediano-grande podrían pertenecer a llama, y se excluyeron los de tamaño pequeño que con seguridad pertenecen a vicuña (Mengoni Goñalons 2013). El sesgo que puede existir en la construcción de estos perfiles se debe a la posible inclusión de especímenes correspondientes a guanaco. Para abordar prácticas cinegéticas se construyeron perfiles etarios a partir de los especímenes óseos restantes, sean fusionados o no, que por su tamaño pequeño pertenecerían a vicuña. La construcción de ambos perfiles se realizó a partir de las frecuencias del MNE, fusionados o no fusionados, para cada uno de los elementos propuestos por Mengoni Goñalons (2013: Tabla 3).

Finalmente, se registraron las modificaciones óseas presentes en los especímenes identificados por taxón. Se analizaron las marcas que fueron resultado de la actividad antrópica: huellas de corte, raspado, machacado, percusión y negativos de impacto (Lyman 1994, 2008; Mengoni Goñalons 1999). También se estudiaron las marcas originadas por otros tipos de agentes y procesos: acción de carnívoros, roedores y raíces (Mengoni Goñalons 1999) y estadios de meteorización (Behrensmeyer 1978).

\section{Métodos para el análisis de fragmentos cerámicos}

Los residuos orgánicos son absorbidos en las matrices cerámicas durante los procesos de preparación, cocción o almacenamiento de los alimentos. La porosidad de la matriz cerámica permite una excepcional preservación 
de los compuestos orgánicos tales como lípidos, carbohidratos y proteínas. La cromatografía gaseosa acoplada a espectrometría de masa (GCMS) es una de las técnicas más utilizadas para investigar residuos de lípidos preservados en los interiores de las vasijas (Colombini y Modugno 2009; Evershed 2008). En tanto, el análisis de isótopos estables de carbono es efectivo para identificar alimentos en residuos lipídicos absorbidos en cerámicas arqueológicas. Esta técnica mide la relación ${ }^{13} \mathrm{C} /{ }^{12} \mathrm{C}$ de los compuestos con carbono -en este caso los lípidosy se expresa en valores de $\delta^{13} \mathrm{C}$. La variación en valores de $\delta^{13} \mathrm{C}$ de los lípidos recuperados responde a que existen plantas $\mathrm{C}_{3}$ y $\mathrm{C}_{4}$ que siguen diferentes caminos fotosintéticos que llevan a distintas relaciones isotópicas ${ }^{13} \mathrm{C} /{ }^{12} \mathrm{C}\left(\mathrm{O}^{\prime}\right.$ Leary 1993). La ventaja de realizar análisis de isótopos estables de carbono de los lípidos extraídos es su efectividad, aún en fragmentos cerámicos cuyos residuos están completamente absorbidos en la matriz y son invisibles al ojo desnudo (Evershed 2008). Además, el análisis de los extractos lipídicos completos permite obtener valores isotópicos de carbono incluso en muestras que presentan mayor estado de degradación de sus compuestos orgánicos, ya que mide los valores de $\delta^{13} \mathrm{C}$ en la mezcla de lípidos intactos y sus productos de degradación (Seinfeld et al. 2009). La técnica analítica más utilizada para este fin es el análisis elemental acoplado a espectrometría de masa de relaciones isotópicas (EA-IRMS).

Se extrajeron y analizaron los lípidos de las cuatro muestras de enseres cerámicos provenientes de San Francisco descriptos anteriormente. Asimismo, se estudiaron muestras de referencia actuales con fines comparativos. Por un lado, ya que se presumía el uso de grasas de camélidos sudamericanos para el sellado de las superficies internas de las vasijas, se analizaron muestras de grasa de llama fresca y charqueada obtenidas de un criadero denominado La Candelaria, situado en la puna jujeña. Por otro lado, debido a que varios autores plantean el uso especializado de los aríbalos y aribaloides para el almacenamiento, transporte y servicio de bebidas alcohólicas en contextos festivos incaicos (Bray 2008; Meyers 1975; Morris y Thompson 1985), se estudiaron plantas asociadas a la fabricación de bebidas alcohólicas tradicionales andinas.
Estas incluyeron variedades de maíz (Zea mays; planta $\mathrm{C}_{4}$ ), algarroba (Prosopis nigra; planta $\mathrm{C}_{3}$ ), chañar (Geoffrea decorticans; planta $\mathrm{C}_{3}$ ) y mistol (Ziziphus mistol; planta $\mathrm{C}_{3}$ ).

Las muestras fueron extraídas, derivatizadas y analizadas por cromatografía gaseosa acoplada a espectrometría de masa (GC-MS) y por análisis elemental acoplado a espectrometría de masa de relaciones isotópicas (EA-IRMS). Los detalles de los protocolos se encuentran en el Texto Complementario 1. Cabe destacar que los estudios geoarqueológicos realizados en el sitio indican una muy baja cantidad de materia orgánica en la matriz sedimentaria arenosa, con valores entre 0,96 y 2,15 por ciento (Kligmann 2009). Además, se estudió con GC-MS una muestra de sedimento arenoso de control externo al sitio que cuyo perfil fue compatible con un sedimento natural sin alteración antrópica. ${ }^{1}$ Estos resultados son los esperables para este ambiente desértico emplazado en una cota de $4000 \mathrm{msnm}$.

\section{Resultados}

\section{Abundancia y diversidad taxonómica}

En San Francisco dominan los especímenes de camélidos. Probablemente, aquellos especímenes considerados como Artiodactyla correspondan a Camelidae dado que no hay evidencia de otro artiodáctilo en el sitio (e.g., Cervidae). El resto de los taxones posee una baja representación, aunque el conjunto del patio posee mayor cantidad y diversidad de taxones (Tabla 1). Tanto las aves como los roedores son más abundantes en el patio que en el R12 y, además, fue posible identificar un espécimen de Phoenicopteridae -posiblemente flamenco andino- y otro de puma en este espacio.

Las mediciones que se realizaron sobre especímenes óseos de camélidos provenientes del R12 $(N=21)$ y del patio $(N=33)$ permitieron identificar camélidos de dos tamaños claramente diferentes y definidos. De los 54 especímenes, el 87,04 por ciento $(N=47)$ son de tamaño pequeño -atribuibles a vicuña- mientras que el restante 12,96 por ciento $(N=7)$ pertenece al grupo grande -asignable a llama- (Figura 2). Dentro de los especímenes considerados como llama, se observan cuatro de tamaño muy grande 
Tabla 1. Diversidad taxonómica del sitio de San Francisco.

\begin{tabular}{|c|c|c|c|c|}
\hline \multicolumn{5}{|c|}{ Diversidad Taxonómica - San Francisco } \\
\hline \multirow[b]{2}{*}{ Taxa } & \multicolumn{2}{|c|}{ Recinto 12} & \multicolumn{2}{|c|}{ Patio } \\
\hline & $\mathrm{N}$ & $\%$ & $\mathrm{~N}$ & $\%$ \\
\hline MAMMALIA (indeterminado) & 15 & 4,53 & 27 & 3,79 \\
\hline Artiodactyla & 26 & 7,85 & 181 & 25,39 \\
\hline Camelidae & 285 & 86,10 & 452 & 63,39 \\
\hline Rodentia & 2 & 0,60 & 25 & 3,51 \\
\hline Chinchillidae & 1 & 0,30 & 7 & 0,98 \\
\hline Puma concolor & 0 & 0,00 & 1 & 0,14 \\
\hline AVES (indeterminado) & 2 & 0,60 & 19 & 2,66 \\
\hline Phoenicopteridae & 0 & 0,00 & 1 & 0,14 \\
\hline Total NISP & 331 & 100,00 & 713 & 100,00 \\
\hline Total NID & 845 & - & 718 & - \\
\hline Total NR & 1176 & - & 1431 & - \\
\hline
\end{tabular}

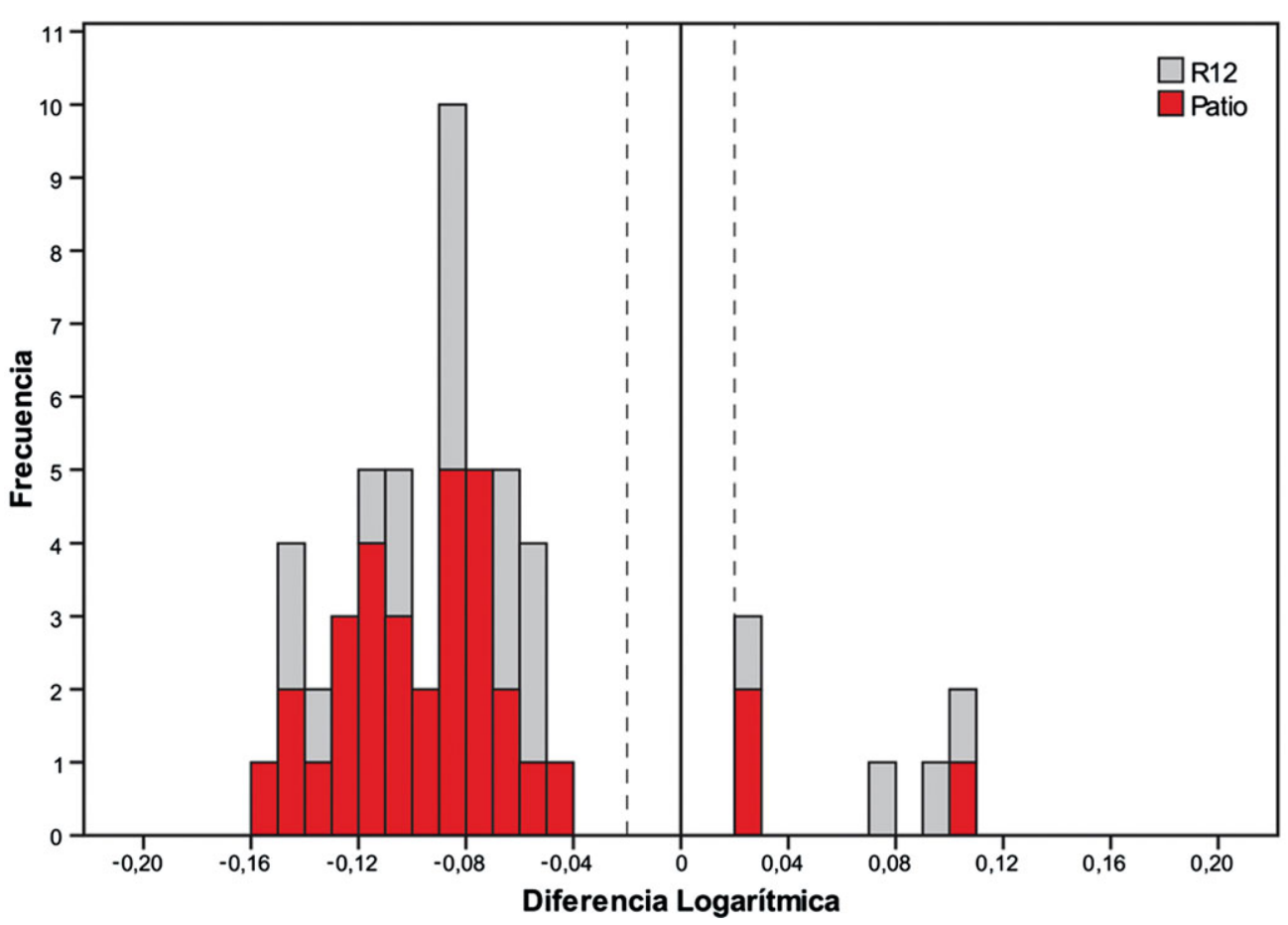

Figura 2. Diferencia de logaritmos entre los casos arqueológicos y el camélido de referencia actual. (Color online)

(intervalo 0,07-0,011), que posiblemente correspondan a llamas cargueras. Los camélidos de tamaño intermedio (intervalo $-0,02-0,02$ ), que podrían pertenecer tanto a guanaco como a llama ("llama-guanaco"), no se encuentran en la muestra. De este modo, solo dos especies de camélidos están representadas en el sitio: llamas y vicuñas, con una clara predominancia de las últimas.

\section{Representación de partes esqueletarias de} camélidos

La gran mayoría de las partes esqueletarias de camélidos se encuentra representada en San Francisco, indicando el ingreso de los animales completos. Hay una clara predominancia de especímenes del esqueleto apendicular, representado por el 83,86 por ciento del NISP en el R12 y por el 79,96 por ciento del NISP en 


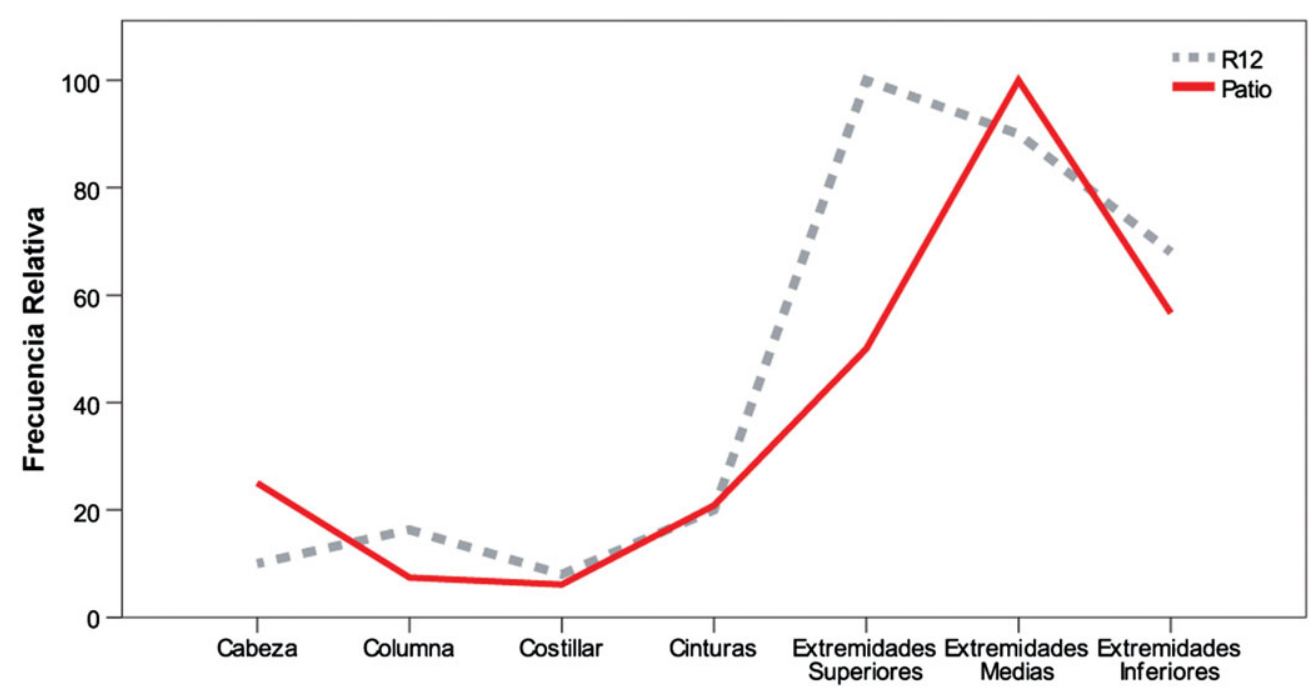

Figura 3. Relación MNEO/MNEE de siete regiones anatómicas de Camelidae. (Color online)

el patio. Si se considera el MNE, la tendencia se mantiene, así como el \%MAU muestra que los elementos apendiculares son aquellos con los valores más elevados en ambas muestras (Tabla Complementaria 1). Estos perfiles anatómicos en los que el esqueleto axial está subrepresentado no se encuentran afectados por procesos dependientes de la densidad mineral ósea. Se correlacionó el \%MAU de 29 elementos óseos (tanto del R12 como del patio) con los valores de densidad ósea de cada uno de ellos obtenidos por Elkin (1995). En ambos casos, los coeficientes de correlación fueron bajos-moderados, positivos y no significativos: $r_{s}=0,36 ; p>0,05$ (R12) y $r_{s}=0,30 ; p>0,05$ (patio).

La relación MNEO/MNEE de camélidos en ambos conjuntos exhibe una abundancia relativa similar de las siete regiones anatómicas (Figura 3). La diferencia más importante se observa en la representación de las extremidades superiores, siendo más abundantes en el conjunto del R12 que en el conjunto del patio. Ambos conjuntos exhiben una baja representación de regiones que ofrecen solo carne (columna, costillar y cinturas). Estas tres unidades anatómicas se caracterizan por ser las más adecuadas para preservarse mediante la técnica de secado, dado que poseen escasa o nula cantidad de médula. Se correlacionó el \%MAU de 15 elementos óseos (tanto del R12 como del patio) con el índice de secado de cada uno de ellos (De Nigris y Mengoni Goñalons 2005). En ambos casos, los coeficientes de correlación fueron altos, negativos y significativos: $r_{s}=-0,68 ; p<0,01$ (R12) y $r_{s}=-0,77 ; p<0,01$ (patio). Aquellas unidades anatómicas que resultan más apropiadas para el secado, y su posterior consumo diferido, se encuentran escasamente representadas en el sitio. En cambio, las unidades anatómicas cuyas características dificultan su secado, y por lo tanto tienden a consumirse de manera directa, son las más abundantes, destacándose las extremidades.

\section{Perfiles etarios}

Los perfiles etarios de vicuña del R12 y del patio no revelan muertes en la primera categoría etaria (menos de 12-18 meses), indicando un 100 por ciento de supervivencia. A partir de la segunda categoría de edad, los perfiles de ambos conjuntos se diferencian: entre un 70-77 por ciento de las vicuñas del R12 sobrevivieron a los 48 meses de edad mientras que en el patio alrededor del 56 por ciento de estos camélidos vivieron más allá de los cuatro años (Figura 4). No obstante, ambos perfiles exhiben una supervivencia relativamente alta de las vicuñas: la mayoría de estos camélidos murieron durante su edad adulta, principalmente luego de los cuatro años de vida.

Los perfiles etarios de llama se construyeron a partir de los estados de fusión de un MNE 

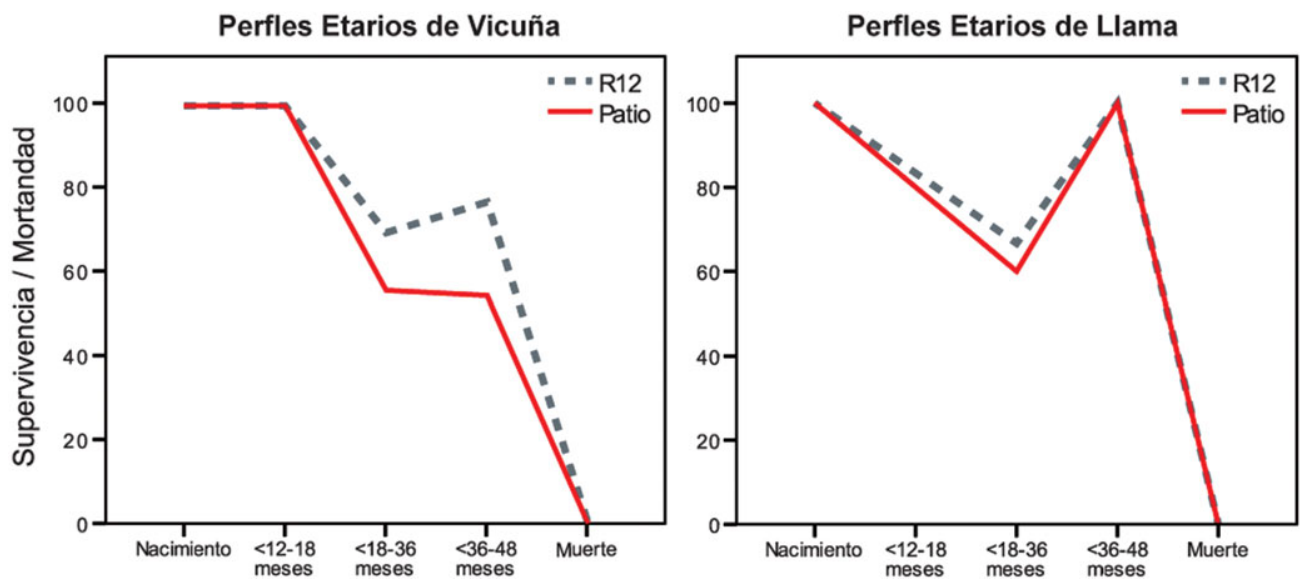

Figura 4. Perfiles etarios de llamas y vicuñas. (Color online)

mucho menor que el utilizado para el caso de las vicuñas. No hay evidencia ósea que otorgue información para la primera categoría etaria (menos de 12-18 meses) de modo tal que solo se presentan los datos de las siguientes dos (Figura 4). Tanto el perfil etario del R12 como el del patio exhiben una tendencia similar: entre un 60-67 por ciento de las llamas sobrevivieron a los 36 meses de edad. Para la siguiente categoría etaria (menos de 36-48 meses), únicamente se observaron huesos fusionados. Cabe destacar que solo se registraron tres elementos óseos fusionados. Este fenómeno sugiere el ingreso de huesos de individuos mayores a los cuatro años de edad al sitio. Si bien la muestra es pequeña y los huesos de la primera y tercera categoría están ausentes y no poseen una representación considerable respectivamente, se sostiene que la mayoría de los camélidos domésticos presentes en San Francisco son adultos. Las muertes de las llamas ocurrieron entre los 18-36 meses de edad, edad óptima como productoras de carne, y principalmente después de los 48 meses.

\section{Modificaciones óseas}

Las marcas de origen antrópico se concentran en los especímenes de Camelidae. Se destacan las huellas de corte, siendo las más frecuentes en ambos conjuntos y encontrándose en la mayoría de las regiones anatómicas, principalmente en aquellas que ofrecen abundante carne: extremidades superiores, columna, costillar y cinturas. Su presencia en estas regiones indica actividades de descarne y desarticulación. Las marcas de corte en rótulas, carpianos y tarsianos indican actividades de desarticulación, tanto de la pata delantera como de la trasera. Las huellas de corte en las extremidades inferiores, relacionadas con el cuereo del animal, están presentes en ambos conjuntos. En segundo lugar en importancia, se destacan las marcas de percusión las cuales se concentran casi exclusivamente en los huesos largos, elementos óseos con médula. En ambos conjuntos aparecen con frecuencias similares, exhibiendo mayor presencia en las extremidades superiores, siguiéndole en importancia las inferiores y, por último, las medias (Tabla 2). Si bien existe variabilidad en el tipo de marcas, las de corte y percusión son las más frecuentes e indicarían distintas etapas del procesamiento de las carcasas: cuereo, desarticulación, descarne y extracción de médula.

No solo los camélidos presentan marcas de procesamiento. Cuatro especímenes de distintos taxones provenientes del patio exhiben marcas antrópicas. Un fragmento de tarsometatarso de Phoenicopteridae posee marcas de corte y machacado. Además, un fragmento de tarsometatarso distal de un ave indeterminada (aunque destacadamente más pequeña que Phoenicopteridae), presenta marcado perimetral. Este tipo de marca -asociada al control de la fractura del hueso y a la obtención de un producto predeterminado- se registra también en un fragmento de fémur distal de Chinchillidae. Con relación a esto, en el sitio se halló un tubo óseo 
Tabla 2. Regiones anatómicas de Camelidae y frecuencia de marcas antrópicas (C: corte; R: raspado; M: machacado; P: percusión).

\begin{tabular}{|c|c|c|c|c|c|c|c|c|c|c|}
\hline \multirow[b]{2}{*}{ Regiones anatómicas de Camelidae } & \multicolumn{5}{|c|}{ R12 } & \multicolumn{5}{|c|}{ Patio } \\
\hline & NISP & $\mathrm{C} \%$ & $\mathrm{R} \%$ & $\mathrm{M} \%$ & $\mathrm{P} \%$ & NISP & $\mathrm{C} \%$ & $\mathrm{R} \%$ & $\mathrm{M} \%$ & $\mathrm{P} \%$ \\
\hline Cabeza (cráneo, bula, mandíbula, hioides) & 18 & 11,1 & - & - & - & 31 & - & - & 6,5 & - \\
\hline $\begin{array}{l}\text { Columna (cervicales, torácicas, lumbares, } \\
\text { sacro) }\end{array}$ & 13 & 30,8 & - & - & - & 17 & 5,9 & - & - & - \\
\hline Costillar (costillas, esternebras) & 13 & 15,4 & 7,7 & - & - & 33 & 15,2 & - & 3,0 & - \\
\hline Cinturas (innominado, escápula) & 4 & - & - & - & - & 6 & 16,7 & - & - & 16,7 \\
\hline Extremidades superiores (húmero, fémur) & 18 & 33,3 & - & - & 16,7 & 30 & 30,0 & - & 3,3 & 16,7 \\
\hline Extremidades medias (radioulna, tibia) & 23 & 8,7 & - & 4,3 & 4,3 & 77 & 6,5 & - & 7,8 & 5,2 \\
\hline $\begin{array}{l}\text { Extremidades inferiores (metapodios, } \\
\text { falanges } 1 \text { y } 2 \text { ) }\end{array}$ & 128 & 14,8 & 1,6 & 0,8 & 7,0 & 165 & 5,5 & - & 0,6 & 7,3 \\
\hline Rótula, carpianos y tarsianos & 47 & 17,0 & - & - & - & 65 & 7,7 & - & - & - \\
\hline Total & 264 & 16,3 & 1,1 & 0,8 & 4,9 & 424 & 8,3 & - & 2,6 & 5,2 \\
\hline
\end{tabular}

cuyas características morfológicas coinciden con las del fémur de Chinchillidae. Finalmente, la falange de Puma concolor exhibe intensas marcas de corte. Son escasos los especímenes de felinos en sitios incas del Collasuyu y la presencia de marcas de procesamiento en sus restos es destacable.

Respecto a las marcas de origen no antrópico, de los 331 especímenes identificados del R12, el 22,96 por ciento $(N=76)$ posee algún tipo de marca de origen no antrópico mientras que de los 713 especímenes del patio el 17,81 por ciento $(N=127)$ posee evidencia de la acción de algún agente no humano. La incidencia de carnívoros es baja en ambos conjuntos (menos del 1 por ciento), en tanto que se registra una acción más intensa de los roedores en el conjunto del R12 (8,16 por ciento) que en el del patio $(1,12$ por ciento). Las raíces fueron el principal agente modificador, tanto de los restos del R12 (16,31 por ciento) como de los del patio (16,55 por ciento). Ambos conjuntos exhiben un excelente estado de conservación: el 90,94 por ciento del NISP del R12 y el 91,58 por ciento del NISP del patio posee estadios de meteorización entre 0 y 1 .

\section{Presencia de Grasa Animal en Fragmentos Cerámicos}

En las cuatro muestras cerámicas analizadas se detectaron los ácidos laúrico (C12:0), mirístico (C14:0), pentadecanoico (C15:0), palmítico (C16:0), palmitoleico (C16:1), margárico
(C17:0), esteárico (C18:0), oleico (C18:1) y en un caso también ácido linoleico (C18:2) (Figura 5, Tabla Complementaria 2). Los perfiles de ácidos grasos indicaron mezclas de aceites vegetales y grasas animales.

En todas las muestras se hallaron cantidades minoritarias de ácidos grasos ramificados anteiso (12-metil-tetradecanoico y 14-metilhexadecanoico) que marcan la presencia de lípidos de animales rumiantes que son resultado del metabolismo de las grasas por la digestión bacteriana ruminal (Martínez Marín et al. 2010) (Figura 5). En particular, esta clase de ácidos grasos ramificados ha sido hallada en camélidos sudamericanos que son pseudo-rumiantes (Maier et al. 2007; Vázquez et al. 2008). Los mismos también fueron detectados en la muestra de grasa de llama analizada en este estudio. Dado que los camélidos sudamericanos son los pseudo-rumiantes más explotados en el oeste tinogasteño en momentos prehispánicos, los ácidos grasos ramificados constituyen verdaderos biomarcadores de estos animales.

Aunque la presencia de lípidos de origen animal en ollas de uso doméstico se atribuye a la cocción de guisos o sopas, en el caso de estos aríbalos y aribaloides los residuos de grasa de camélidos podrían indicar el sellado de las paredes internas para contener líquidos de manera eficiente, evitando la pérdida de los mismos por difusión a través de la matriz cerámica (Henrickson y McDonald 1983; Schiffer 1990; Skibo 1992). Este argumento se sostiene porque (a) 

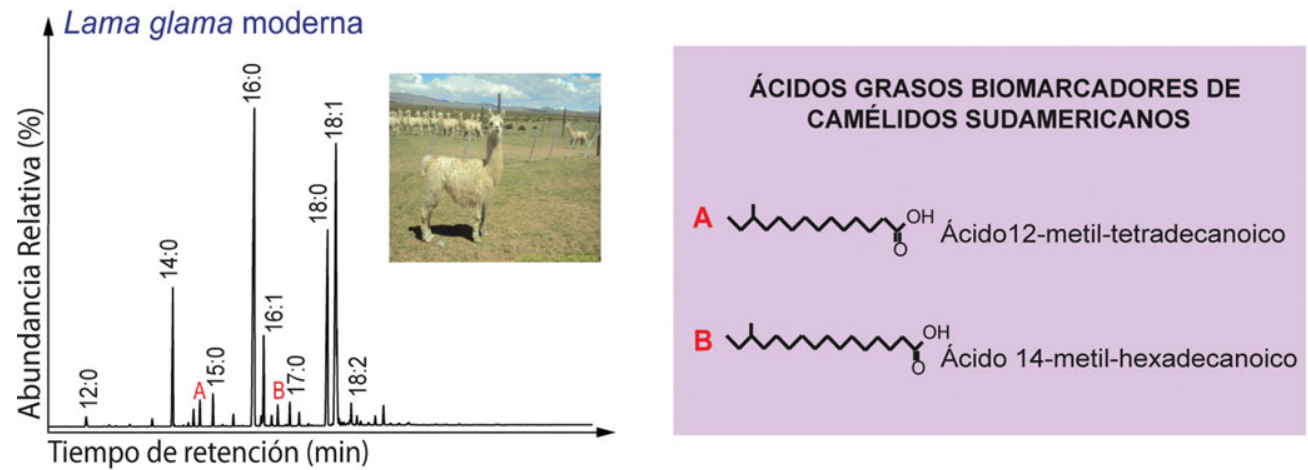

\section{A-01}

A-02
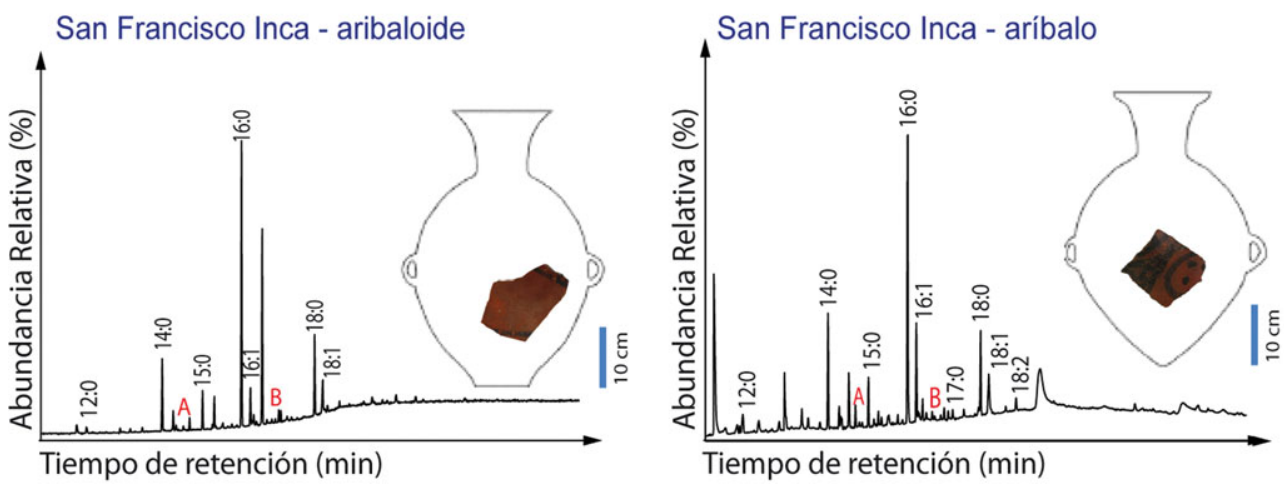

A-03

\section{A-04}
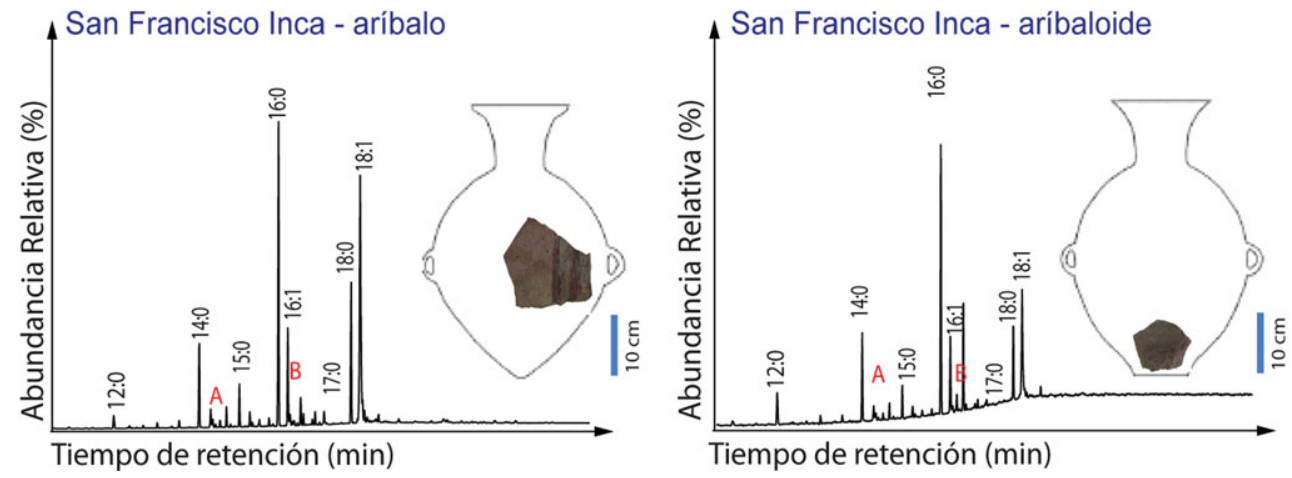

Figura 5. Perfiles de ácidos grasos y presencia de biomarcadores de camélidos sudamericanos en residuos orgánicos recuperados de aríbalos y aribaloides de San Francisco. (Color online)

los aríbalos y aribaloides tienen características morfológicas inadecuadas para cocer alimentos, ya que el cuello es sumamente restringido y no permite el adecuado acceso al contenido de la vasija para incorporar ingredientes, revolver, o servir los mismos; (b) ningún ejemplar presenta evidencia de exposición al fuego ni rastros de hollín; y (c) este tipo de vasijas fueron muy preciadas en el pasado y tenían la función específica de almacenar, transportar y servir bebidas alcohólicas en festividades rituales (Bray 2008).

Además de la grasa de camélidos, en los aríbalos se hallaron aceites vegetales formando parte de complejas mezclas. Los valores isotópicos de 


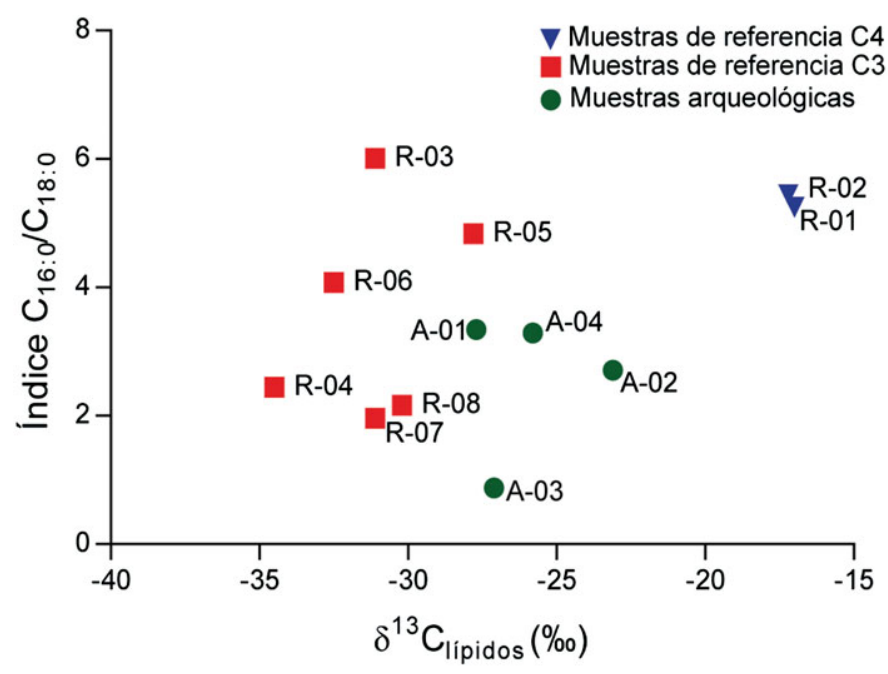

Figura 6. Relación entre los valores $\delta^{13} C_{\text {lípidos }} \mathrm{y}$ el índice $C_{16: 0} / C_{18: 0}$. (Color online)

$\delta^{13} \mathrm{C}$ y los porcentajes de aporte de aceites de plantas $\mathrm{C}_{4}$ indicaron que los residuos lipídicos de las muestras arqueológicas no son homogéneos (Tabla Complementaria 2). La relación entre los valores de $\delta^{13} \mathrm{C}$ y el índice $\mathrm{P} / \mathrm{E}\left(\mathrm{C}_{16: 0} / \mathrm{C}_{18: 0}\right)$, que responde al origen animal o vegetal de los lípidos (Eerkens 2005), también dio información del origen de los mismos (Figura 6). La muestra con mayor aporte de $\mathrm{C}_{4}$ es la A-02 (60,6 por ciento), que además tiene una importante cantidad de aceites vegetales (índice $\mathrm{P} / \mathrm{E}=2,7$ ), también apoyado por la presencia de tetracosanol, un alcohol graso de origen vegetal. El perfil de ácidos grasos y el valor isotópico de los lípidos indican que, además de ser impermeabilizada con grasa de camélidos, esta vasija posiblemente contuvo chicha de maíz. En el otro extremo, la muestra A-01 tiene el menor aporte $\mathrm{C}_{4}$ (31 por ciento) y tiene una importante cantidad de aceites vegetales (índice $\mathrm{P} / \mathrm{E}=3,3$ ). La similitud con los aceites de algarroba, chañar o mistol sugiere que en este caso la vasija fue sellada y luego almacenó una bebida alcohólica elaborada con plantas $\mathrm{C}_{3}$, tal como la aloja de tradición local preincaica. La muestra A-04 tiene un valor isotópico comparable a mezclas de plantas $\mathrm{C}_{3} \mathrm{y}$ $\mathrm{C}_{4}\left(43,2\right.$ por ciento de aporte $\left.\mathrm{C}_{4}\right)$ y un buen aporte de aceites vegetales (índice $P / E=3,3$ ). Esto indicaría que la vasija fue tratada con grasa y luego contuvo tanto chicha como aloja, probablemente de manera alternada. Por último, la muestra A-03 tiene un índice $\mathrm{P} / \mathrm{E}$ bajo $(0,9)$ que sugiere poca incidencia de los aceites vegetales y se asemeja al índice típico de grasa animal. Su valor isotópico apunta a un valor intermedio entre $\mathrm{C}_{3}$ y $\mathrm{C}_{4}$. Esta vasija tiene una señal pobre de la bebida que potencialmente contuvo, posiblemente por degradación o bien porque fue usada muy poco tiempo. Los residuos están dominados por la señal del tratamiento de su superficie interna con grasa de camélido.

\section{Discusión y Conclusiones}

Los resultados obtenidos permiten aproximarnos a las prácticas humanas relacionadas con los animales durante la ocupación incaica del oeste tinogasteño. A continuación se discute la importancia de los camélidos y las diferentes modalidades de su consumo, el empleo de animales y sus productos con fines tecnológicos y las distintas estrategias implementadas en el manejo de la fauna silvestre y doméstica.

En San Francisco se explotaron y consumieron fundamentalmente camélidos. Los datos osteométricos indican que los silvestres (vicuñas) predominan ampliamente por sobre los domésticos (llamas). El análisis de la representación de las partes esqueletarias y de las marcas de origen antrópico sugieren que los camélidos fueron ingresados completos al sitio, con posterioridad a lo cual se realizaron 
distintos tipos de actividades de procesamiento: cuereo, desarticulación, descarne y extracción de médula. La alta representación de huesos de las extremidades y sus marcas asociadas indican el consumo directo de estas unidades, tanto de carne como de médula. Estos alimentos fueron compartidos durante las fiestas patrocinadas por el Estado en el sitio y fueron acompañados con el consumo bebidas fermentadas (Lantos et al. 2015). La baja representación de la columna, el costillar y las cinturas de los camélidos sugieren dos escenarios: a) el descarte de la gran mayoría de estas partes anatómicas en otros sectores del sitio no intervenidos; o b) el consumo directo y descarte de una baja proporción de estas partes anatómicas en el sitio y el secado del resto y su posterior traslado a otros sitios para el consumo diferido. Respecto a esto último, la puna posee una excelente condición ambiental para el secado de la carne: escasa humedad y noches frías (Miller y Burger 2000; Stahl 1999). Además, se ha registrado el uso de charki de vicuña como forma de tributo durante momentos incaicos (Murra 2002). Así, nos inclinamos por el segundo de los escenarios presentados.

Los animales también se utilizaron con fines tecnológicos. En primer lugar, los análisis químicos revelaron el potencial empleo de grasa animal para el tratamiento de las superficies internas de aríbalos y aribaloides de San Francisco con el objetivo de sellar las paredes porosas y hacerlas aptas para contener bebidas. La grasa empleada corresponde a camélidos, tal como lo indica el hallazgo de ácidos grasos biomarcadores. Dada la escasa grasa subcutánea e intramuscular de los camélidos, se propone que se utilizó médula ósea para este propósito. Su ventaja radica en que es grasa que no se encuentra acompañada de carne que pueda pudrirse y generar malos olores o sabores que afecten la calidad de la bebida alcohólica almacenada. Además, la médula ósea se torna líquida al calentarla, lo cual es ideal para verter dentro de estos contenedores cerámicos que tienen cuellos estrechos y dificultan el acceso a su interior para frotar las paredes con grasa sólida. Es interesante destacar que estudios de procedencia de bienes cerámicos indican que gran parte de los aríbalos y aribaloides recuperados en San Francisco fueron manufacturados en Batungasta, centro de producción alfarero emplazado en el valle de Fiambalá (Ratto et al. 2002 , 2004). En este sentido, resulta muy probable que el proceso de impermeabilización de los aríbalos y aribaloides también haya sido efectuado en Batungasta, completando así el proceso de manufactura. Posteriormente, estos contenedores habrían sido llenados con chicha o aloja para luego ser transportados hacia San Francisco. Si bien no se descarta la producción de bebidas fermentadas en la puna, la cota altitudinal de $4000 \mathrm{msnm}$ no presentaría las mejores condiciones para llevar a cabo los procesos de fermentación. En este sentido, solo la experimentación en altura de la elaboración de bebidas fermentadas podrá aportar conocimiento respecto a dicho proceso. Más allá de dónde fuera hecha la impermeabilización de las vasijas, se destaca que durante momentos de la ocupación incaica del oeste tinogasteño, se empleó grasa de camélidos para tal fin tecnológico.

En segundo lugar, se destaca el uso de las llamas como animales de carga. Los datos osteométricos y etarios indican que estos camélidos domésticos fueron empleados como medio de transporte. En este sentido, y considerando que la mayor parte de las piezas cerámicas recuperadas en San Francisco fueron manufacturadas en Batungasta, resulta probable que el transporte de las vasijas haya sido realizado mediante caravanas de llamas que articularon el valle de Fiambalá con la puna transicional de Chaschuil a través de conectores naturales (Ratto et al. 2012). Además, otros animales fueron empleados con fines tecnológicos. Así, huesos de aves y de chinchíllidos presentan evidencias de haber sido utilizados para la manufactura de artefactos, como por ejemplo tubos óseos. No se descarta el aprovechamiento de las plumas de las aves, considerando que este uso se encuentra registrado durante momentos incaicos para el adorno de vestimentas y la confección de ornamentos (Murra 2002).

Finalmente, el manejo de animales fue realizado mediante dos tipos de estrategias: el pastoreo y la caza. En primer lugar, la presencia de llamas sugiere el empleo de estrategias pastoriles. Por un lado, y como se mencionó anteriormente, las llamas fueron utilizadas como animales de carga. Por otro lado, se observa 
que ciertas llamas fueron sacrificadas en su edad óptima como productoras de carne, lo que indica que su uso estuvo dirigido al aprovechamiento de recursos primarios. De este modo, San Francisco presenta evidencia de una estrategia pastoril mixta, en la cual se aprovechan los recursos alimentarios y la capacidad de carga que brindan las llamas. Sin embargo, y a diferencia de lo que puede ocurrir en sitios de pastores, en San Francisco no se organizaron las actividades en torno a la estrategia pastoril. El pastoreo de llamas no estructuró las actividades del sitio sino que las llamas fueron animales especialmente trasladados desde otros sitios para cumplir con demandas específicas (principalmente, trasporte). En segundo lugar, la clara predominancia de animales silvestres indica el empleo de estrategias de caza, lo cual también se registra en sitios incaicos de puna como Miño 2 (Labarca y López 2006) y Tambo Cañapa (Nielsen et al. 2006). Entre ellos, se destacan animales de suma importancia simbólica para los incas: las vicuñas. Los perfiles etarios indican que la caza estuvo dirigida principalmente a vicuñas de más de cuatro años de edad. Esto concuerda con lo esperado para la matanza selectiva ocurrida durante el chaku, en el cual se sacrificaban animales adultos y se esquilaban y liberaban al resto de las vicuñas. Las muertes de las vicuñas menores a 36 meses de edad registradas en el sitio pueden asignarse a la matanza dirigida a animales jóvenes enfermos, lo cual también se encuentra documentado en las fuentes que describen el chaku (Ratto y Orgaz 2004). Mediante el control de la matanza, se evitaba la sobreexplotación de la especie, conformándose así la caza de vicuñas como una actividad sustentable (Yacobaccio 2009). Otra práctica desarrollada durante el chaku era la matanza de predadores (Ratto y Orgaz 2008). El puma es el único predador natural de las vicuñas de modo que la presencia de un espécimen óseo de este felino en San Francisco puede relacionarse con esta actividad. Sin embargo, es necesario destacar la importancia simbólica del puma en la esfera política y religiosa incaica. En Cusco, las pieles de puma eran exhibidas durante el taqui Coyo-Aucayo, danza en la cual se realizaban ofrendas solicitando por los jóvenes que acababan de iniciarse como guerreros (Molina
2008 [1573]). Si bien la única falange de puma con marcas de corte hallada en San Francisco no resulta concluyente respecto al procesamiento de su piel, consideramos que es un hallazgo extraordinario y no debe dejar de ser mencionado.

La combinación del análisis zooarqueológico de restos óseos con el estudio químico de residuos orgánicos preservados en la matriz cerámica de aríbalos y aribaloides resulta novedosa en el área andina y otorga la posibilidad de ampliar el conocimiento acerca del uso de la fauna. De este modo, se abordaron las distintas estrategias empleadas en el manejo de los animales (caza, chaku y pastoreo) así como también el aprovechamiento de los diversos recursos que brindan (carne, médula, huesos, fibra, transporte). Así, fue posible discutir las múltiples dimensiones de las prácticas humanas relacionadas a la fauna, concluyendo que durante la ocupación incaica del oeste tinogasteño los animales -y particularmente los camélidos- fueron objeto de un uso nutricional, tecnológico y simbólico.

Agradecimientos. A Mariana De Nigris, Guillermo Mengoni Goñalons, Rafael Labarca, Gabriel López y Patricio López por las sugerencias bibliográficas. A Matías Medina por la ayuda en la identificación taxonómica. A Marta Maier del UMYMFOR (UBA-CONICET) y Héctor Panarello del INGEIS (UBA-CONICET), con quienes se realizaron los análisis químicos e isotópicos, respectivamente. Las investigaciones se realizaron en el marco del proyecto de la Agencia Nacional de Promoción Científica y Tecnológica PICT-20120196, dirección Norma Ratto.

Declaración de disponibilidad de datos. Los datos utilizados se encuentran disponibles tanto en la presente publicación como en otros trabajos ya publicados. En caso de que sean necesarios datos más detallados, éstos pueden ser solicitados a los autores.

Materiales complementarios. Los materiales complementarios están vinculados a la versión digital de este artículo y son accesibles a https://doi.org/10.1017/laq.2016.7. Estos incluyen los siguientes archivos:

Tabla Complementaria 1. NISP, NISP\%, MNE, MNE\%, MAU y MAU\% de cada parte esqueletaria de Camelidae de los conjuntos arqueofaunísticos de San Francisco.

Tabla Complementaria 2. Valores isotópicos de carbono y perfiles de ácidos grasos y lípidos neutros de muestras de aríbalos y aribaloides de San Francisco.

Texto Complementario 1. Protocolos de extracción y análisis de los lípidos. 


\section{Referencias Citadas}

Bárcena, Roberto, Pablo Cahiza, Jorge García Llorca y Sergio Martín

2008 Arqueología del sitio inka de La Alcaparrosa. Parque Nacional San Guillermo. Provincia de San Juan, República Argentina. Monografías Xama, Mendoza.

Behrensmeyer, Anna

1978 Taphonomic and Ecologic Information from Bone Weathering. Paleobiology 4(2):150-162.

Berenguer, José

2007 El camino Inka del Alto Loa y la creación del espacio provincial en Atacama. En Procesos Sociales Prehispánicos en los Andes Meridionales, editado por Axel Nielsen, María C. Rivolta, Verónica Seldes, Pablo Mercolli y María Vázquez, pp. 413-443. Editorial Brujas, Córdoba.

Berenguer, José, Cecilia Sanhueza y Iván Cáceres

2011 Diagonales incaicas, interacción interregional y dominación en el altiplano de Tarapacá, Norte de Chile. En En Ruta: Arqueología, historia y etnografía del tráfico sur andino, editado por Lautaro Nuñez y Axel Nielsen, pp. 247-283. Encuentro Grupo Editor, Córdoba.

Binford, Lewis

1978 Nunamiut Ethnoarchaeology. Academic Press, New York.

1984 Faunal Remains from Klasies River Mouth. Academic Press, Orlando, Florida.

Borrero, Luis

1990 Fuego-Patagonian Bone Assemblages and the Problem of Communal Guanaco Hunting. En Hunters of the Recent Past, editado por Leslie Davis y Brian Reeves, pp. 373-399. Unwin Hyman, London.

Bray, Tamara

2008 The Role of Chicha in Inca State Expansion. En Drink, Power, and Society in the Andes, editado por Justin Jennings y Brenda J. Bowser, pp. 108-132. University Press of Florida, Gainesville.

Cartajena, Isabel, Bárbara Rivera, Patricio López y Boris Santander

2014 Introducción de Taxones Domésticos y Control de Camélidos en el Norte Semiárido: Variabilidad Osteométrica en el Valle de Mauro, IV Región, Chile. Revista Chilena de Antropología 30:98-103.

Colombini, María, y Francesca Modugno (editoras)

2009 Organic Mass Spectrometry in Art and Archaeology. Wiley, Chichester.

Couso, María, Reinaldo Moralejo, Marco Giovannetti, Luis Del Papa, María Páez, Julia Gianelli, Laura Giambelluca, Marcelo Arnosio y Rodolfo Raffino

2011 Análisis de la variabilidad material del Recinto 1 Kancha II: aportes para una comprensión de la política incaica en el Shincal de Quimivil. Arqueología 17:3555.

D'Altroy, Terrance

2002 The Incas. Blackwell Publishing, Oxford.

DÁltroy, Terrance, Ana Lorandi, Verónica Williams, Milena Calderari, Christine Hastorf, Elizabeth Demarrais y Melissa Hagstrum

2000 Inka Rule in the Northern Calchaquí Valley, Argentina. Journal of Field Archaeology 27(1):1-26.

Dedenbach-Salazar Saenz, Sabine

1990 Inka Pachaq Llamanpa Willaynin: Uso y Crianza de los Camélidos en la Época Incaica. Estudio lingüístico y etnohistórico basado en las fuentes lexicográficas y textuales del primer siglo después de la conquista. Bonner Amerikanistische Studien, Bonn.

De Nigris, Mariana

2004 El consumo en grupos cazadores recolectores: un ejemplo zooarqueológico de Patagonia meridional. Publicaciones de la Sociedad Argentina de Antropología, Buenos Aires.

De Nigris, Mariana, y Guillermo Mengoni Goñalons

2005 The Guanaco as a Source of Meat and Fat in the Southern Andes. En The Zooarchaeology of Fats, Oils and Dairying, editado por Jacqui Mulville y Alan Outram, pp. 60-166. Oxbow Books, Oxford.

Eerkens, Jelmer

2005 GC-MS Analysis and Fatty Acid Ratios of Archaeological Potsherds from the Western Great Basin of North America. Archaeometry 47(1):83-102.

Elkin, Dolores

1995 Volume Density of South American Camelid Skeletal Parts. International Journal of Osteoarchaeology 5:29-37.

Elkin, Dolores, Celina Madero, Guillermo Mengoni Goñalons, Daniel Olivera y Hugo Yacobaccio

1991 Avances en el estudio arqueológico de los camélidos en el noroeste argentino. Trabajo presentado en la VII Convención Internacional de Especialistas en Camélidos Sudamericanos, San Salvador de Jujuy.

Evershed, Richard

2008 Organic Residue Analysis in Archaeology: The Archaeological Biomarker Revolution. Archaeometry 50(6):895-924.

Garceau, Charles, Virginia McRostie, Rafael Labarca, Francisco Rivera y Rubén Stehberg

2010 Investigación arqueológica en el sitio Tambo Ojos de Agua. Cordillera del Aconcagua. Actas del XVII Congreso Nacional de Arqueología Chilena, Tomo I: 351-363. Sociedad Chilena de Arqueología, Universidad Austral.

García Llorca, Jorge

1995 Estudio arqueológico del Recinto 4 Unidad D Sector II del Tambo de Tambillos, Uspallata (Mendoza, Argentina). Relaciones de la Sociedad Argentina de Antropología 20:163-188.

Giovannetti, Marco

2015 Agricultura, regadío y molienda en una capital Inkaica: Los sitios El Shincal y Los Colorados, Noroeste Argentino. British Archaeological Reports, Oxford.

Henrickson, Elizabeth, y Mary McDonald

1983 Ceramic Form and Function: An Ethnographic Search and an Archeological Application. American Anthropologist 85(3):630-643.

Kligmann, Débora

2009 Procesos de Formación de Sitios Arqueológicos: Tres Casos de Estudio en la Puna Meridional Catamarqueña Argentina. British Archaeological Reports, Oxford.

Labarca, Rafael, y Patricio López

2010 Los conjuntos arqueofaunísticos de Miño 2 (Norte de Chile): Evidencias de festines y relaciones de poder dentro del sistema vial inkaico. Actas del XVII Congreso Nacional de Arqueología Chilena, Tomo II:1379-1388. Sociedad Chilena de Arqueología, Universidad Austral.

Lantos, Irene, Jorge Spangenberg, Marco Giovanetti, Norma Ratto y Marta Maier

2015 Maize Consumption in Pre-Hispanic South-central Andes: Chemical and Microscopic Evidence from Organic Residues in Archaeological Pottery from 
Western Tinogasta (Catamarca, Argentina). Journal of Archaeological Science 55:83-99.

Lema, Verónica, Marco Giovanetti, Cecilia Deschamps, Aylen Capparelli y Rodolfo Raffino

2009 Análisis de restos faunísticos en el sitio inkaico El Shincal (Catamarca, Argentina). Comparación con información arqueobotánica y análisis cerámico. En La alimentación en la América precolombina colonial: Una aproximación interdisciplinaria, editado por Aylen Capparelli, Alexandre Chevalier y Raquel Piqué, pp. 97-112. Consejo Superior de Investigaciones Científicas, Madrid.

López, Gabriel

2003 Pastoreo y caza de camélidos en el Temprano de la Puna de Salta: Datos osteométricos del sitio Matancillas 2. Intersecciones en Antropología 4:17-27.

López, Patricio, Isabel Cartajena, Boris Santander, Daniel Pavlovic y Daniel Pascual

2015 Camélidos domésticos en el Valle de Mauro (Norte Semiárido, Chile): Múltiples análisis para un mismo problema. Intersecciones en Antropología 16:101114.

Lyman, R. Lee

1994 Vertebrate Taphonomy. Cambridge University Press, Cambridge.

2008 Quantitative Paleozoology. Cambridge University Press, Cambridge.

Madero, Celina

1994 Ganadería incaica en el noroeste argentino: Análisis de la arqueofauna de dos poblados prehispánicos. Relaciones de la Sociedad Argentina de Antropología 19:145-163.

Madrazo, Guillermo, y Marta Ottonello

1966 Tipos de instalación prehispánica en la región de la Puna y su borde. Monografías I, Olavarría.

Maier, Marta, Delia de Faria, María Boschín, Sara Parera y Florencia Bernal del Castillo

2007 Combined Use of Vibrational Spectroscopy and GC-MS Methods in the Characterization of Archaeological Pastes from Patagonia. Vibrational Spectroscopy 44(1):182-186.

Malpass, Michael (editor)

1993 Provincial Inca: Archaeological and Ethnohistorical Assessment of the Impact of the Inca State. University of Iowa Press, Iowa City.

Malpass, Michael, y Sonia Alconini (editores)

2010 Distant Provinces in the Inka Empire: Toward a Deeper Understanding of Inka Imperilism. University of Iowa Press, Iowa City.

Martínez Marín, Andrés, Manuel Pérez-Hernández, Luis Pérez Alba, Gustavo Gómez Castro y Domingo Carrión Pardo

2010 Metabolismo de los lípidos en los rumiantes. REDVET, Revista electrónica de Veterinaria 11(8):16957504.

Meadow, Richard

1987 Techniques for Comparing Bone Measurement Data from Small Samples. Trabajo presentado en Northeastern Faunal Analysis Conference, Connecticut.

Mengoni Goñalons, Guillermo

1999 Cazadores de guanacos de la estepa Patagónica. Publicaciones de la Sociedad Argentina de Antropología, Buenos Aires.

2007 Camelid Management during Inca Times in N.W. Argentina: Models and Archaeozoological Indicators. Anthropozoologica 42(2):129-141.
2008 Camelids in Ancient Andean Societies: A Review of the Zooarchaeological Evidence. Quaternary International 185:59-68.

2013 El aprovechamiento de la fauna en sociedades complejas: aspectos metodológicos y su aplicación en diferentes contextos arqueológicos del NOA. En $A l$ borde del imperio. Paisajes sociales, materialidad y memoria en áreas periféricas del noroeste argentino, compilado por Verónica Williams y María B. Cremonte, pp. 311-396. Publicaciones de la Sociedad Argentina de Antropología, Buenos Aires.

Meyers, Albert

1975 Algunos problemas en la clasificación del estilo incaico. Pumapunku 8:7-25.

Miller, George, y Richard Burger

2000 Ch'arki at Chavin: Ethnographic Models and Archaeological Data. American Antiquity 65:573-576.

Molina, Cristóbal de

2008 [1573] Relación de las fábulas y ritos de los Incas. Editado por Julio Pérez y Henrique Urbano. Fondo Editorial de la Universidad de San Martín de Porres, Lima.

Morris, Craig, y Donald Thompson

1985 Huánuco Pampa: An Inca City and Its Hinterland. Thames and Hudson, London.

Murra, John

2002 El mundo andino: población, medio ambiente y economía. Fondo Editorial Pontificia Universidad Católica del Perú e Instituto de Estudios Peruanos, Lima.

Nielsen, Axel, José Berenguer y Cecilia Sanhueza

2006 El Qhapaqñan entre Atacama y Lípez. Intersecciones en Antropología 7:217-234.

Nielsen, Axel, Pablo Mercolli y Norma Nasif

2010 Ocupaciones temporarias y explotación faunística en la Región Lacustre Altoandina. Actas del XVII Congreso Nacional de Arqueología Chilena, Tomo II: 1365 1378. Sociedad Chilena de Arqueología, Universidad Austral.

O'Leary, Marion

1993 Biochemical Basis of Carbon Isotope Fractionation. En Stable Isotopes and Plant Carbon-Water Relations, editado por James R. Ehleringer, Anthony E. Hall y Graham D. Farquhar, pp. 19-28. Academic Press, San Diego.

Olivera, Daniel

1997 La importancia del Recurso Camelidae en la Puna de Atacama entre los 10.000 y 500 años AP. Estudios Atacameños 14:29-41.

Olivera, Daniel, Silvina Vigliani, Alejandra Elías, Lorena Grana y Pablo Tchilinguirian

2005 La ocupación Tardío-Inka en la Puna Meridional: El sitio Campo Cortaderas. Cuadernos del Instituto Nacional de Antropología y Pensamiento Latinoamericano 20:257-277.

Orgaz, Martín, y Norma Ratto

2015 Estrategias de Ocupacion Incaica al Sur del Tawantinsuyu (Tinogasta, Catamarca, Argentina): La Apropiacion de Paisajes Sagrados y La Memoria Social. Nawpa Pacha, Journal of Andean Archaeology 35(2): 217-235.

Orgaz, Martín, Anabel Feely y Norma Ratto

2007 La cerámica como expresión de los aspectos socio-políticos, económicos y rituales de la ocupación Inka en la puna de Chaschuil y el valle de Fiambalá (dpto. Tinogasta, Catamarca). En Procesos sociales prehispánicos en el sur andino, editado por Axel 
E. Nielsen, María C. Rivolta, Verónica Seldes, María M. Vázquez y Pablo Mercolli, pp. 239-250. Editorial Brujas Córdoba.

Raffino, Rodolfo

1981 Los Inkas del Kollasuyu. Ramos Americana, La Plata.

Ratto, Norma

2013 A modo de introducción: la articulación de estudios arqueológicos, paleoambientales e históricos en el oeste tinogasteño (Catamarca). En Delineando prácticas de la gente del pasado: Los procesos socio-históricos del oeste catamarqueño, compilado por Norma Ratto, pp. 17-44. Publicaciones de la Sociedad Argentina de Antropología, Buenos Aires.

Ratto, Norma, Mara Basile y Anabel Feely

2012 Rutas y Espacios Conectados: Las Tierras Altasy Bajas del Oeste Tinogasteño de Catamarca (Ca. 2001.200 d.C.). Revista Chilena de Antropología 26:33-58. Ratto, Norma, y Martín Orgaz

2004 La cacería en los Andes: registro material del chaku en la Puna meridional catamarqueña (Cazadero Grande, Dpto Tinogasta, Catamarca). Arqueología 12:72102.

2008 Transformaciones sociales de la Cacería Comunal de Vicuñas desde los Inkas hasta las comunidades andinas actuales. En Zooarqueología hoy: Encuentros hispano-argentinos, editado por J. Carlos Diez, pp. 109122. Universidad de Burgos, Burgos.

Ratto, Norma, Martín Orgaz y Rita Plá

2002 Producción y distribución de bienes cerámicos durante la ocupación Inca entre la región puneña de Chaschuil y el valle de Abaucán (Dpto. Tinogasta, Catamarca). Relaciones de la Sociedad Argentina de Antropología 27:271-301.

2004 La Explotación del Alfar de La Troya en el Tiempo: Casualidad o Memoria (Dpto. Tinogasta, Catamarca, Argentina). Chungara 36(2):349-361.

Rivera, Bárbara, Patricio López, Isabel Cartajena y Boris Santander

2014 Caracterización de las Ocupaciones de los Períodos Intermedio Tardío y Tardío ( 1.000-1.536 años D.C.) en el Valle de Mauro (IV Región, Chile) a partir del Registro Zooarqueológico. Revista Chilena de Antropología 30:129-135.

Rodríguez Loredo, Cecilia

1998 Estudio arqueozoológico del sitio inca PotreroChaquiago, Barrios La Solana y Retambay, Andalgalá, Pcia. de Catamarca (Argentina). Relaciones de la Sociedad Argentina de Antropología 22-23:203-245.

Schiffer, Michael

1990 The Influence of Surface Treatment on Heating Effectiveness of Ceramic Vessels. Journal of Archaeological Science 17(4):373-381.

Seinfeld, Daniel, Christopher von Nagy y Mary Pohl

2009 Determining Olmec Maize Use through Bulk Stable Carbon Isotope Analysis. Journal of Archaeological Science 36(11):2560-2565.

Skibo, James

1992 Pottery Function: A Use-Alteration Perspective. Plenum Press, New York.

Stahl, Peter

1999 Structural Density of Domesticated South American Camelid Skeletal Elements and the Archaeological Investigation of Prehistoric Andean Ch'arki. Journal of Archaeological Science 26:1347-1368.
Troncoso, Andrés, Cristian Becker, Daniel Pavlovic, Paola González, Jorge Rodríguez y Claudia Solervicens 2009 El sitio LV099-B "Fundo Agua Amarilla" y la ocupación del período incaico en la costa de la provincia del Choapa, Chile. Chungara 41(2):241-259.

Troncoso, Andrés, Daniel Pavlovic, Cristian Becker, Paola González y Jorge Rodríguez

2004 Césped 3, asentamiento del período DiaguitaIncaico sin cerámica diaguita fase III en el curso superior del Río Illapel, IV Región, Chile. Chungara 36(2):893906.

Vázquez, Cristina, Mara Maier, Sara Parera, Hugo Yacobaccio y Patricia Solá

2008 Combining TXRF, FT-IR and GC-MS Information for Identification of Inorganic and Organic Components in Black Pigments of Rock Art from Alero Hornillos 2 (Jujuy, Argentina). Analytical and Bioanalytical Chemistry 391(4):1381-1387.

von den Driesch, Angela

1976 A Guide to the Measurement of Animal Bones from Archaeological Sites. Peabody Museum of Archaeology and Ethnology, Cambridge.

Williams, Verónica

2000 El imperio Inka en la provincia de Catamarca. Intersecciones en Antropología 1:55-78.

Williams, Verónica, Calogero Santoro, Álvaro Romero, Jesús Gordillo, Daniela Valenzuela y Vivien Standen

2009 Dominación Inca en los Valles Occidentales (Sur del Perú y Norte de Chile) y el Noroeste Argentino. En Andes. Boletín del Centro de Estudios Precolombinos de la Universidad de Varsovia $N^{\circ} 7$, editado por Mariusz Ziółkowski, Justin Jennings, Luis Belan Franco y Andrea Drusini, pp. 615-654. Warsaw University Press, Varsovia.

Yacobaccio, Hugo

2009 The Historical Relationship between People and the Vicuña. En The Vicuña: Theory and Practice of Community-Based Wildlife Management, editado por Iain J. Gordon, pp. 7-20. Springer, New York.

Yacobaccio, Hugo, Celina Madero, Marcela Malmierca y María Reigadas

1998 Caza, domesticación y pastoreo de camélidos en la Puna Argentina. Relaciones de la Sociedad Argentina de Antropología 22-23:389-418.

\section{Notas}

1. La concentración de lípidos (en $\mathrm{mg}$ ) por gramo de muestra de sedimento fue pobre $(0,01 \mathrm{mg} / \mathrm{g})$ comparado con las concentraciones de las cuatro piezas cerámicas analizadas, que oscilan entre 0,12 y $0,43 \mathrm{mg} / \mathrm{g}$. Asimismo, el perfil cromatográfico del sedimento control únicamente dio picos de muy baja intensidad de los ácidos palmítico y esteárico, y una ausencia total de los demás ácidos grasos que aparecen en los perfiles de las muestras cerámicas. Este perfil se corresponde con uno típico de sedimento natural sin alteración antrópica. Por lo tanto, consideramos que dada la pobreza en materia orgánica del sitio, es improbable que haya existido una migración de compuestos orgánicos desde la matriz sedimentaria hacia las muestras arqueológicas.

Submitted June 15, 2016; Revised November 7, 2016; Accepted November 30, 2016 